\title{
Combined Immunodeficiency Due to MALT1 Mutations, Treated by Hematopoietic Cell Transplantation
}

\author{
Divya Punwani • Haopeng Wang • Alice Y. Chan • \\ Morton J. Cowan • Jacob Mallott • Uma Sunderam • \\ Marianne Mollenauer • Rajgopal Srinivasan • \\ Steven E. Brenner • Arend Mulder • Frans H. J. Claas • \\ Arthur Weiss • Jennifer M. Puck
}

Received: 19 August 2014 / Accepted: 26 December 2014 / Published online: 28 January 2015

(C) The Author(s) 2015. This article is published with open access at Springerlink.com

\begin{abstract}
Purpose A male infant developed generalized rash, intestinal inflammation and severe infections including persistent cytomegalovirus. Family history was negative, T cell receptor excision circles were normal, and engraftment of maternal cells was absent. No defects were found in multiple genes associated with severe combined immunodeficiency. A 9/10 HLA matched unrelated hematopoietic cell transplant (HCT) led to mixed chimerism with clinical resolution. We sought an underlying cause for this patient's immune deficiency and dysregulation.
\end{abstract}

Divya Punwani and Haopeng Wang contributed equally to the work.

Electronic supplementary material The online version of this article (doi:10.1007/s10875-014-0125-1) contains supplementary material, which is available to authorized users.

D. Punwani · A. Y. Chan · M. J. Cowan · J. Mallott • J. M. Puck ( $\bowtie)$ Department of Pediatrics, University of California San Francisco

School of Medicine, and UCSF Benioff Children's Hospital, Box 0519, 513 Parnassus Avenue, HSE-301A, San

Francisco, CA 94143-0519, USA

e-mail: puckj@peds.ucsf.edu

H. Wang $\cdot$ M. Mollenauer $\cdot$ A. Weiss

Department of Medicine, Rosalind Russell Medical Research Center for Arthritis and Howard Hughes Medical Institute, University of California San Francisco School of Medicine, San

Francisco, CA 94143, USA

\section{S. E. Brenner}

Department of Plant and Microbial Biology, University of California, Berkeley, CA 94720-3102, USA

U. Sunderam $\cdot$ R. Srinivasan

Innovations Labs, Tata Consulting Services, Hyderabad, AP, India

A. Mulder $\cdot$ F. H. J. Claas

Department of Immunohematology and Blood Transfusion, Leiden

University Medical Centre, Leiden, The Netherlands
Methods Clinical and laboratory features were reviewed. Whole exome sequencing and analysis of genomic DNA from the patient, parents and 2 unaffected siblings was performed, revealing 2 MALT1 variants. With a host-specific HLA-C antibody, we assessed MALT1 expression and function in the patient's post-HCT autologous and donor lymphocytes. Wild type MALT1 cDNA was added to transformed autologous patient $\mathrm{B}$ cells to assess functional correction.

Results The patient had compound heterozygous DNA variants affecting exon 10 of MALT1 (isoform a, NM_006785.3), a maternally inherited splice acceptor c.1019-2A $>\mathrm{G}$, and a de novo deletion of c.1059C leading to a frameshift and premature termination. Autologous lymphocytes failed to express MALT1 and lacked NF-KB signaling dependent upon the CARMA1, BCL-10 and MALT1 signalosome. Transduction with wild type MALT1 cDNA corrected the observed defects. Conclusions Our nonconsanguineous patient with early onset profound combined immunodeficiency and immune dysregulation due to compound heterozygous MALT1 mutations extends the clinical and immunologic phenotype reported in 2 prior families. Clinical cure was achieved with mixed chimerism after nonmyeloablative conditioning and HCT.

Keywords BCL10 - bone marrow transplant/hematopoietic cell transplant $\cdot$ CARD11 $\cdot$ CARMA1 $\cdot$ combined immunodeficiency (CID) · erythroderma $\cdot$ immune dysregulation

\section{Introduction}

Identification of the genetic causes of human immunodeficiencies has revealed the roles of many factors critical for 
human lymphocyte development and function. Combined immunodeficiencies (CIDs) listed by the IUIS Expert Committee on Primary Immunodeficiencies [1], include a wide spectrum of gene defects underlying susceptibility to bacterial, viral and fungal infections. The most profound of these, collectively termed severe combined immunodeficiency (SCID), are disorders with few to absent autologous T cells and absent cellular and humoral immune function [1-4]. In contrast, many CID gene defects do not abrogate development or release into the periphery of $\mathrm{T}$ and $\mathrm{B}$ cells, but instead disrupt pathways critical for their effector and regulatory roles; examples are ORAI-I, STIM-1 [5], and MHC class II deficiency [6]. While over 14 different SCID genes are known [7], many patients with CID without $T$ cell lymphopenia have as yet unidentified genetic defects. Whole exome sequencing (WES) may identify molecular causes of CID.

Studies in knockout mice and human malignancies and immunodeficiencies have delineated the intracellular signaling pathways activated by engagement of lymphocyte antigen receptors and G-protein coupled receptors [8]. NF- $\mathrm{kB}$, a central mediator of activation signals, translocates from the cytoplasm into the nucleus to initiate transcription of genes that bring about lymphocyte maturation, activation and proliferation [9]. $\mathrm{NF}-\mathrm{KB}$ activation and signaling is in turn controlled by multiple mechanisms, one of which is the signalosome formed from assembly of CARMA1 (also called CARD11), BCL-10 and MALT1 into the "CBM" signaling complex [10, 11]. While the precise molecular mechanisms are still not completely clear, stimulation through the T cell and B cell receptors causes phosphorylation of CARMA1, recruitment of MALT1 and BCL-10, and oligomerization of components of the CBM complex [12-14]. This in turn activates the IKB kinase complex through TNF receptor-associated factor 6 (TRAF6)-mediated ubiquitination of NF- $\mathrm{KB}$ essential modulator (NEMO) [15-17], leading to phosphorylation and proteasomal degradation of the inhibitor $\mathrm{I} \mathrm{B} \alpha$ and release of NF- $\mathrm{kB}$. Thus, it is not surprising that defects in NEMO, CARMA1 and MALT1 have been found to cause human CID [18-23].

We describe a new patient in whom CID and immune dysregulation due to MALT1 compound heterozygous mutations was successfully treated by allogeneic hematopoietic cell transplantation (HCT). This case in a non-consanguineous family, combined with 2 prior reports [22-24], broadens the spectrum of MALT1 deficiency disease and suggests an effective treatment.

\section{Methods}

Patient

After informed consent, as approved by the University of California San Francisco Committee on Human Research, the patient, his parents and 2 healthy siblings were studied with whole exome sequencing and immunological assessments.

\section{DNA Studies}

Genomic DNA from the patient, obtained prior to HCT, and from his parents and siblings was subjected to WES. Analysis tools were similar to [25], with modifications detailed in the Supplementary methods. DNA variants were confirmed by Sanger sequencing. With parental consent, residual dried blood spots obtained in the newborn nursery were recovered from the California Department of Public Health Newborn Screening Program, and $\mathrm{T}$ cell receptor excision circles (TRECs) were analyzed as described [26].

\section{Cell Separations and Reagents}

After HCT from an unrelated donor differing at a single HLA-C locus, the patient developed mixed chimerism of the hematopoietic system. Patient alleles were HLA-C *08:01, $*$ 03:04; donor alleles were *08:01, *07:02. Staining cells with monoclonal human IgM antibody (clone ID: TRA2G9) recognizing antigens encoded by $C^{*} 01 / * 03 / * 04: 01 /$ *14:02, but not $\mathrm{C}^{*} 07 / * 08$ [27-29], followed by PE-anti-human IgM (clone MHM-88), permitted separation of autologous patient lymphocytes from those of the donor by flow cytometry. For specific antibodies see Supplementary methods.

\section{PCR and Western Blotting}

RNA was isolated from sorted autologous patient PBMCs obtained post-HCT (RNeasy kit, Qiagen), and expression of MALT1 transcripts (primers in Suppl Table 1) was detected by PCR (Superscript III system, Life Technologies) followed by Sanger sequencing. The sorted cells were also lysed with $1 \%$ NP-40 and analyzed by Western blotting using antibodies recognizing MALT1 (EP603Y, Abcam) and BCL-10 (H-197, Santa Cruz Biotechnologies).

Intracellular Signaling Assays

For phosphorylation assays PBMCs or Epstein-Barr virus (EBV) transformed B cells were stimulated with $400 \mathrm{nM}$ PMA and $250 \mathrm{ng} / \mathrm{ml}$ ionomycin at $37{ }^{\circ} \mathrm{C}$, for $10 \mathrm{~min}$. For cytokine assays PBMCs were stimulated for $6 \mathrm{~h}$ with PMA plus ionomycin; $200 \mathrm{ng} / \mathrm{ml}$ superantigen staphylococcal enterotoxin E (SEE, Toxin Technology, Inc.) plus $4 \mathrm{ug} /$ $\mathrm{ml}$ anti-CD28 clone 9.3; or 1:500 anti-CD3 clone Leu-4 ascites plus $4 \mathrm{ug} / \mathrm{ml}$ anti-CD28. The cells were then fixed, permeabilized (Invitrogen Solutions A and B, Life Technologies) and incubated with either phospho- 
specific unconjugated antibodies followed by anti-rabbitPE, or anti-mouse-FITC labeled secondary antibodies, or
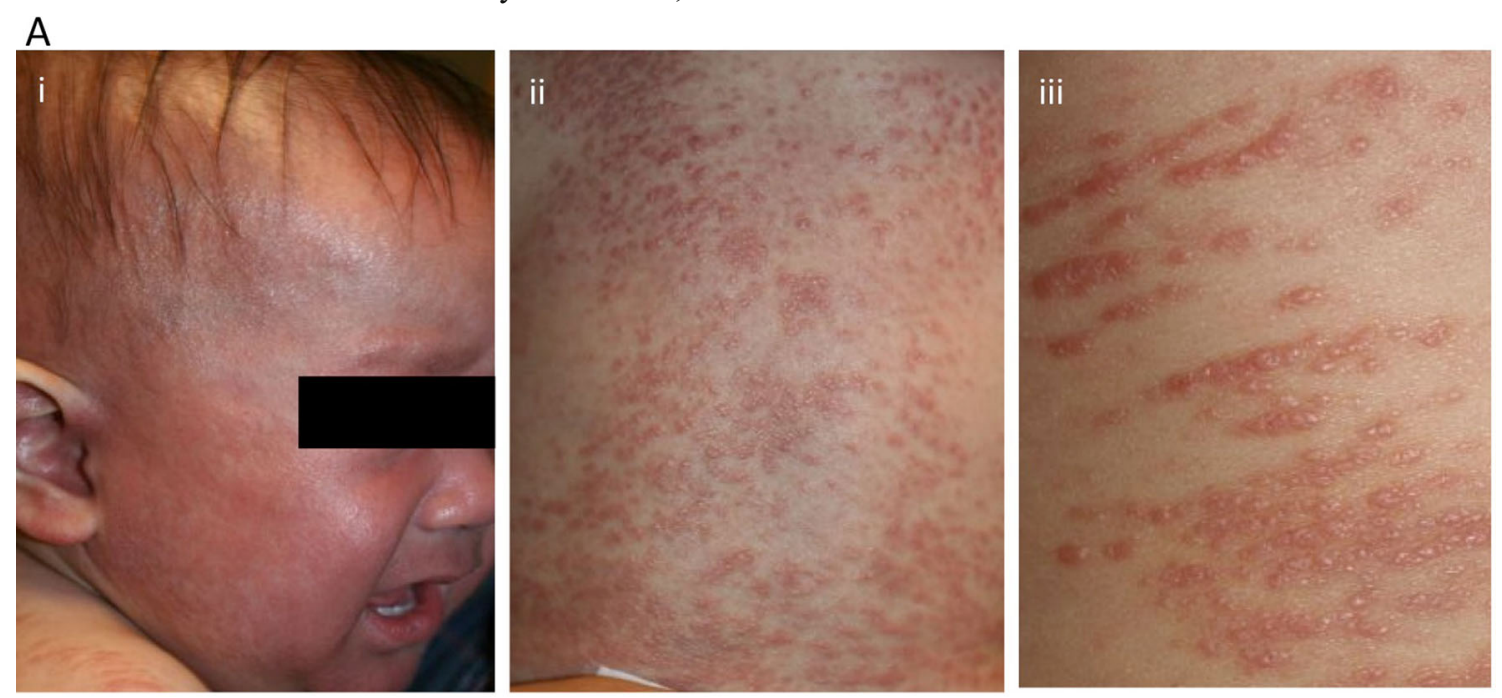

B

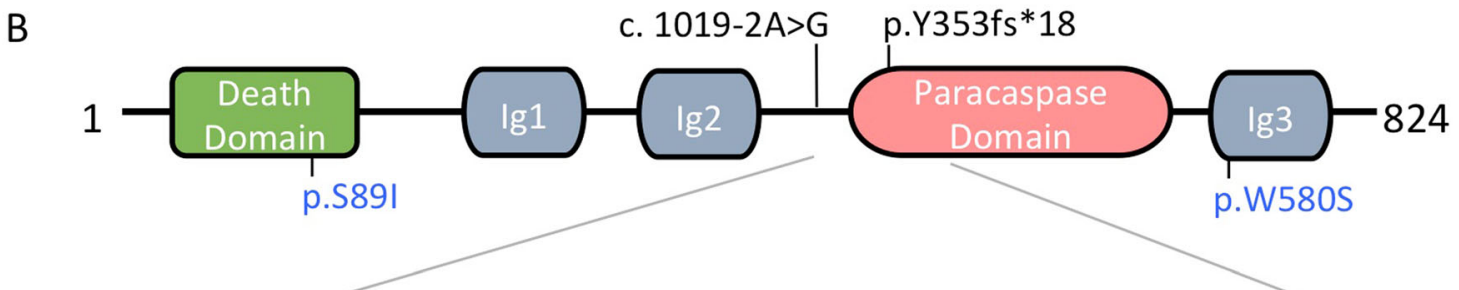

C

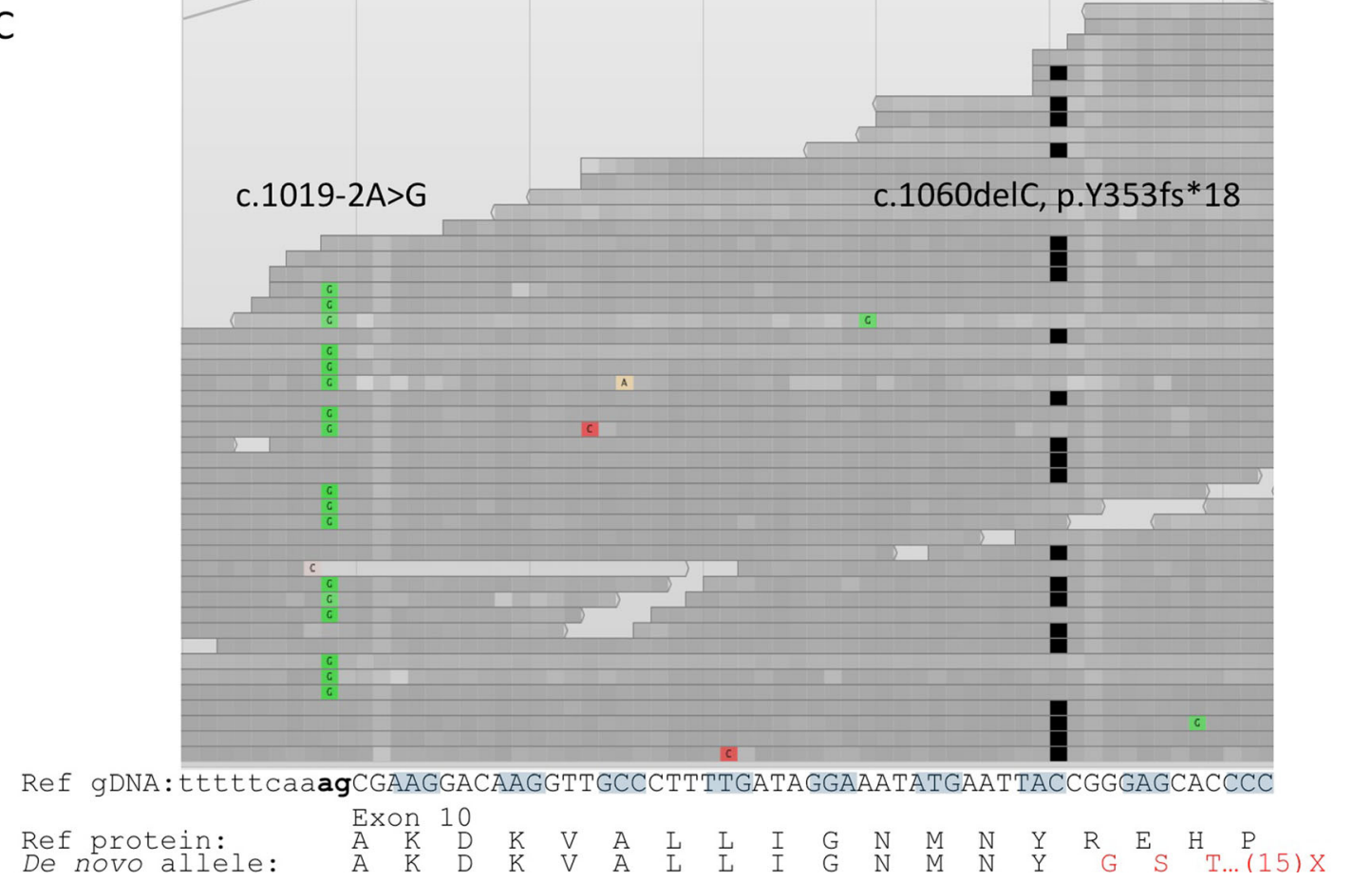

Fig. 1 a, Skin lesions, showing (i) facial erythroderma (ii) dorsal trunk and (iii) close-up with linear distribution of lesions corresponding to excoriations. b, Schematic representation of MALT1 protein (isoform a, NP 006776.1), illustrating death domain, 3 immunoglobulin (Ig)-like domains, and paracaspase domain [30]. Mutations are shown for our patient (black) and prior homozygous cases (blue) [22, 23]. c, Browser view of patient stacked DNA sequence tracks, demonstrating $>30 \mathrm{X}$ antibodies against IL-2 or IFN- $\gamma$. Fluorescent antibodies to relevant surface markers were included. 


\section{Lentivirus Transduction}

MALT1 cDNA (Genecopia) was ligated into lentiviral vector MP-283: pSicoR-BstXI-EF1a-puro-T2A-mCherry, (kindly provided by Michael McManus, Lentiviral RNAi Core, UCSF). MP-283-MALT1 lentiviral supernatant prepared by transient transfection of 293 cells in DMEM medium with $10 \%$ fetal calf serum (FCS) was used to transduce EBV cells in plates pre-coated with Rectronectin (Takara, Japan). After two $24 \mathrm{~h}$ infections, the EBV cells were washed and expanded in RPMI 1640 medium with GlutaMax (Invitrogen), $20 \%$ FCS, penicillin, and streptomicin. MP-283 lentivirus prepared as above without the insert was used in parallel. Transduced cells were detected by mCherry fluorescence.

\section{Results}

\section{Patient History}

The infant, born at term to non-consanguineous parents with negative family history, developed blood-streaked diarrhea and a desquamating, erythematous pruritic rash, the latter evolving into firm erythematous papules affecting trunk, palms and soles (Fig. 1a, Table 1). There were no indications of environmental atopy; IgE was undetectable, and steroids were ineffective. Skin biopsies showed perivascular lymphocytic infiltration in the dermis. Following monthly otitis media infections, an immune workup showed expansion of CD4 and CD8 T cell populations with high proportions of naïve CD45RA T cells, but impaired in vitro proliferative responses (Tables 1 and 2). Maternal T cell engraftment was absent, and the newborn dried blood spot, retrieved from the time of the patient's birth, had 627 T cell receptor excision circles (TRECs) $/ \mu \mathrm{L}$ (normal $>40$ ). B and NK cells were present, but low immunoglobulin levels and absent antibody responses to vaccines necessitated immunoglobulin infusions. The patient experienced poor weight growth, stomatitis, oral thrush, RSV bronchiolitis, and CMV viremia and CMV pneumonitis.

At 18 months of age, following non-ablative conditioning with $120 \mathrm{mg} / \mathrm{kg}$ cyclophosphamide, $140 \mathrm{mg} / \mathrm{m}^{2}$ melphalan and $8 \mathrm{mg} / \mathrm{kg}$ rabbit anti-thymocyte globulin, the patient received peripheral mobilized CD34-selected cells from a 9 of 10 HLA antigen-matched unrelated donor (differing at one HLA-C locus). The patient received $4.85 \times 10^{6} \mathrm{CD} 34$ cells $/ \mathrm{kg}$ and $14.72 \times$ $10^{6} \mathrm{CD} 3$ cells $/ \mathrm{kg}$. Graft versus host disease (GVHD) prophylaxis included methotrexate and cyclosporine, and no GVHD was observed. The patient's rash resolved within 4 weeks and did not return. Donor $\mathrm{T}$ cell function was established by 5 months post-HCT. However, diarrhea and CMV viremia, refractory to gancyclovir and foscarnet treatment, continued until both resolved promptly following infusion 12 months post-HCT of donor $\mathrm{T}$ cells that had been pulsed in vitro with CMV peptide and expanded. Immunoglobulin replacement has been given post-HCT, but donor B cell chimerism, IgA, IgM and anti-A IgM isohemagglutinins are now detectable.

\section{Identification of Mutations in MALT1}

Sequencing of a comprehensive panel of known SCID genes revealed no mutations. To search for disease-causing variants,

Table 1 Clinical course, indicating infections, autoimmune manifestations, treatments (in italics) and times at which samples were obtained for study

\begin{tabular}{ll}
\hline Age & Clinical manifestation \\
\hline $1-3$ months & Bloody stool, erythroderma (later biopsy showing lymphocyte infiltration) \\
9 months & $\begin{array}{c}\text { Poor growth }(<5 \% \text { weight, } 5 \% \text { height), hospitalization for prolonged fever, presumed bacterial } \\
\text { infections responding to systemic antibiotics; S. aureus superinfection of rash }\end{array}$ \\
10 months & IgG infusions instituted \\
13 months & Thrush, candida esophagitis \\
& Continuous antibiotic prophylaxis started \\
& DNA isolated from PBMCs, later used for whole exome sequencing \\
& Persistent CMV $>3,000$ copies by PCR from blood, lung washings despite gancyclovir and foscarnet \\
& treatment; ground glass pneumonitis; self limited RSV bronchiolitis; diarrhea with C. difficile \\
15 months & Hematopoietic cell transplant from $9 / 10$ HLA matched unrelated donor \\
19 months & Rash resolved, donor T cells detected; no graft vs. host disease \\
23 months & Graft vs. host disease prophylaxis discontinued \\
& Lymphocyte proliferation to PHA $>50 \%$ normal, persistent CMV viremia 1,500 copies \\
& PBMCs isolated, separated into autologous patient and donor populations for in vitro functional studies \\
30 months & Antibiotic prophylaxis discontinued \\
6 years & Donor T cell infusion for persistent CMV viremia \\
& CMV viremia resolved, gaining weight (25\% for age) \\
& Donor B cell function detected with normal IgM and IgA, positive IgM isohemagglutinin \\
\hline
\end{tabular}




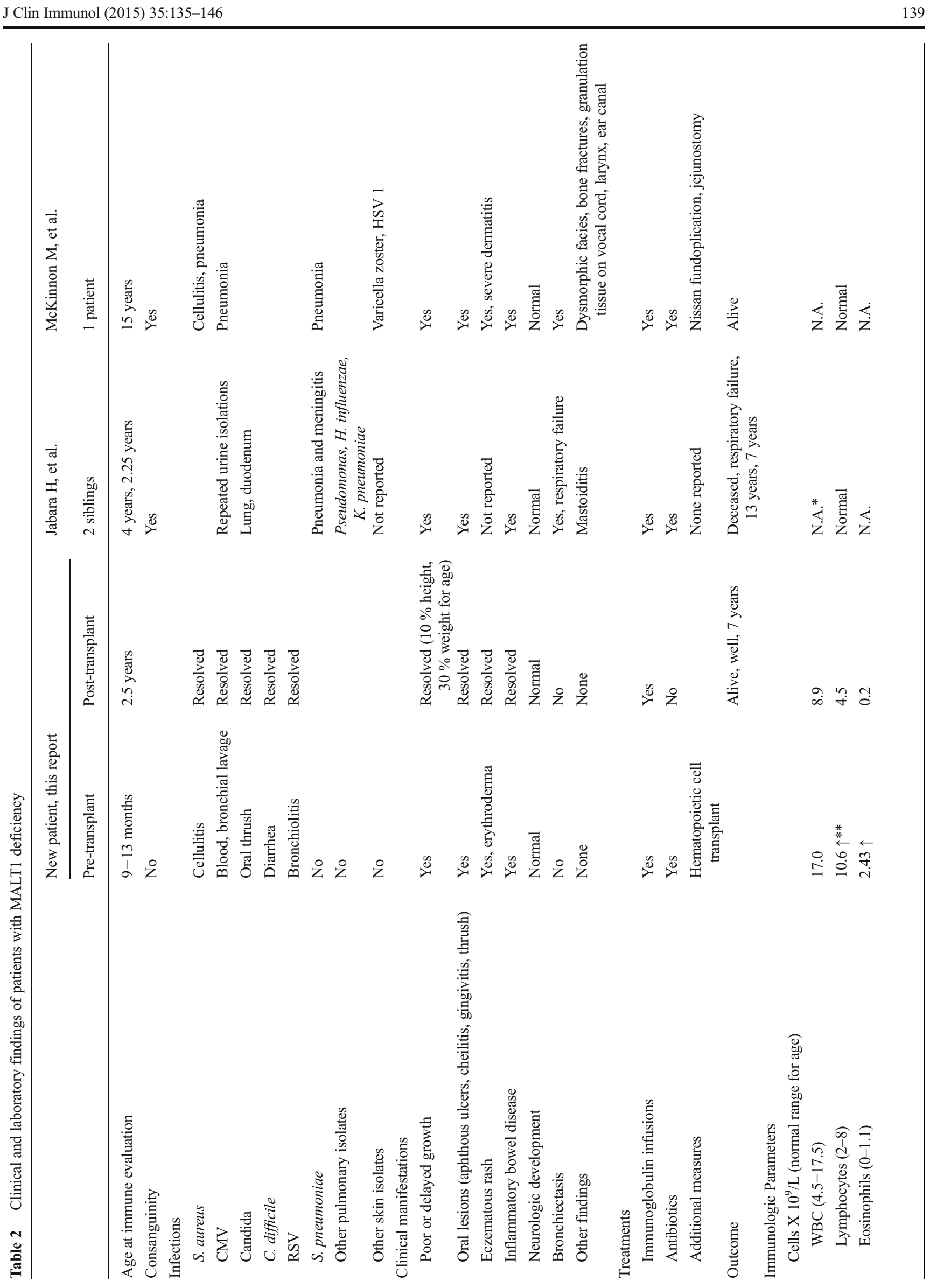

글 Springer 


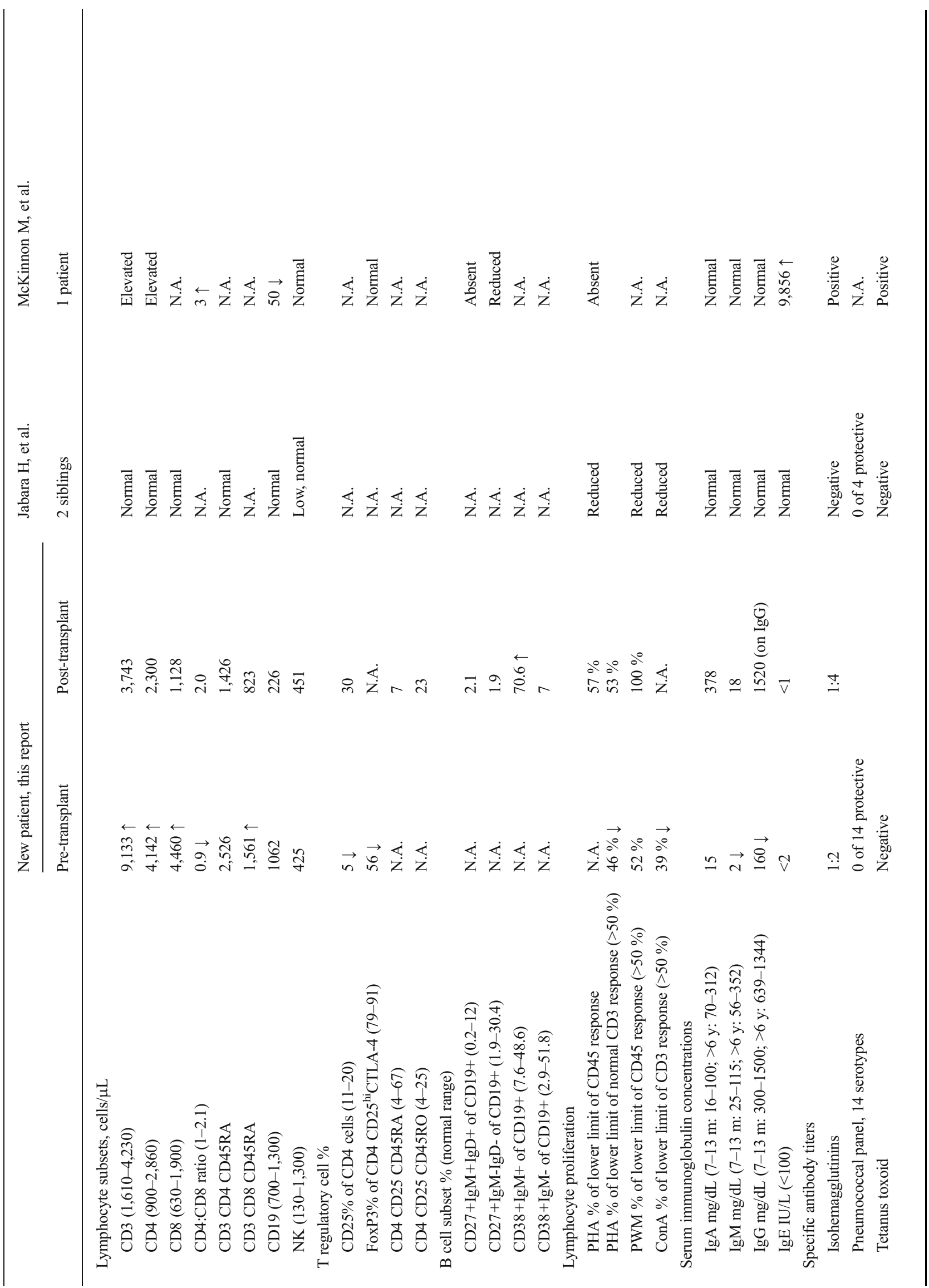




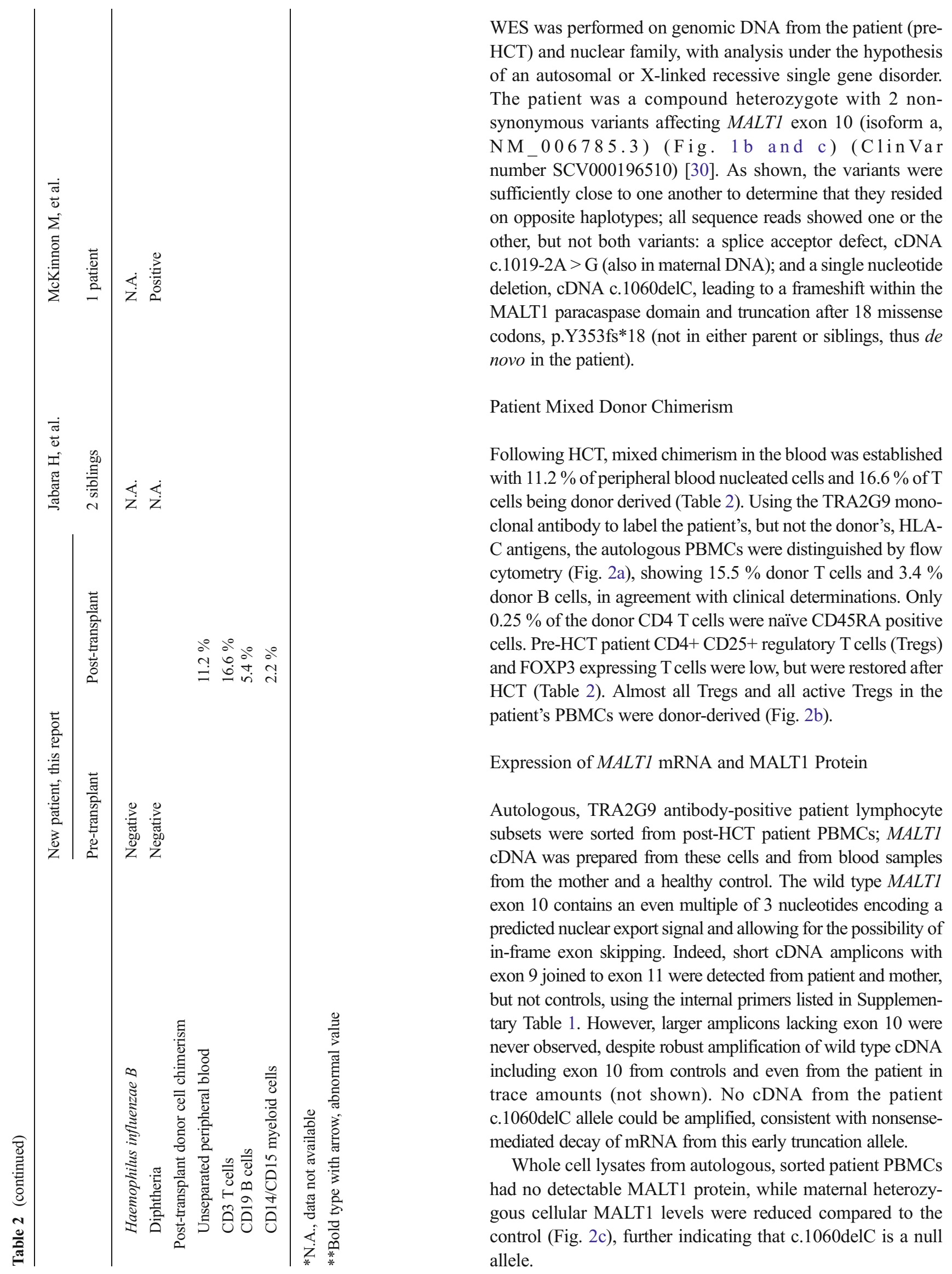


A
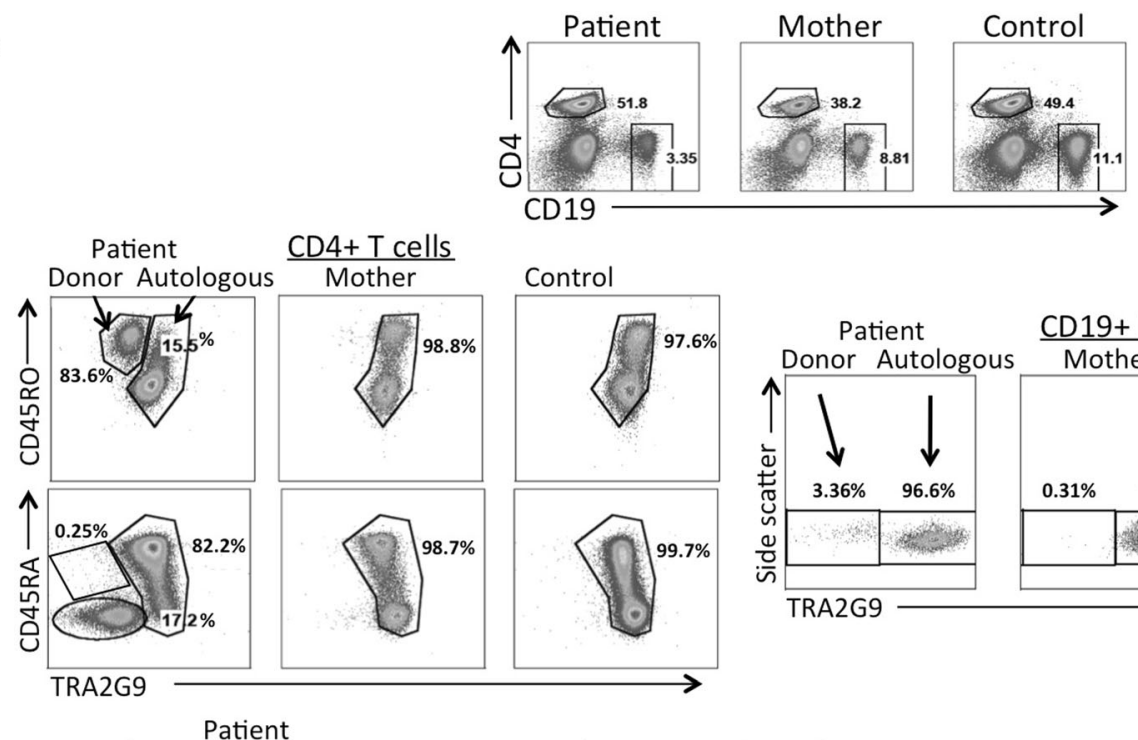

B
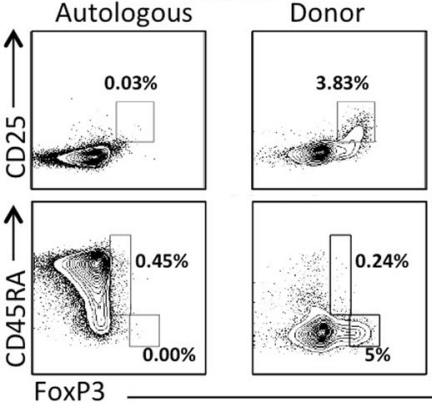

Fig. 2 a, Flow cytometry of PBMCs from the patient, mother and a healthy control, using the TRA2G9 antibody to separate patient autologous cells expressing HLA-C*01/*03/*04:01/*14:02 from donorderived cells expressing *08:01, *07:02. Left panels, naïve CD4+, CD45RA or CD4+ CD45RO+ T cells; right panels, CD19 B cells. b, Upper panels, total Treg cells (CD25+, FoxP3+); lower panels, resting

Functional Consequences of MALT1 Mutations in PBMCs

Phosphorylation of NF- $\mathrm{kB}$ and degradation of I $\mathrm{KB}$ following stimulation were analyzed to indicate the status of the CBM signalosome in PBMCs from the patient, his mother and a control. The patient's autologous cells, identified by staining with the TRA2G9 antibody, were unable to phosphorylate NF-KB or degrade IKB (Fig. 3a, left and right panels, respectively), while cells from the mother and control cells demonstrated equivalent levels of NF- $\mathrm{KB}$ phosphorylation and IKB degradation in naïve and memory T cells as well as B cells. As noted above, too few donor-derived naïve $\mathrm{T}$ cells were detected in the patient's blood to analyze. Phosphorylation of Erk, P38 and S6, each independent of the CBM signalosome, was intact in autologous patient cells, demonstrating selectivity of the MALT1 defect (Suppl Figure 1).

We also examined downstream effects of MALT1dependent NF-KB signaling. After activation with PMA and ionomycin, donor-derived memory T cells and naïve and memory $\mathrm{T}$ cells from the mother and control had abundant IL-2 and

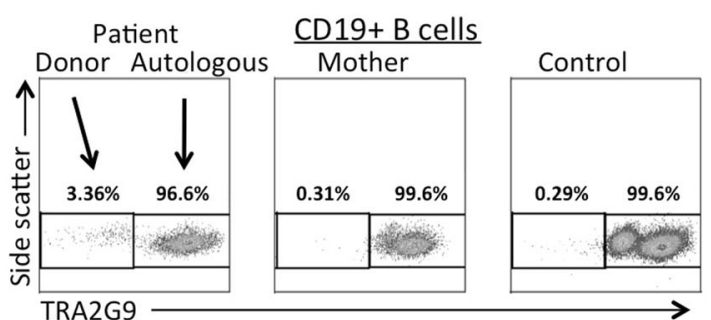

Control

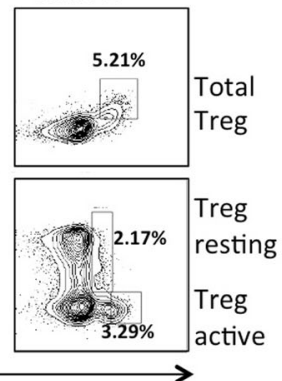

C

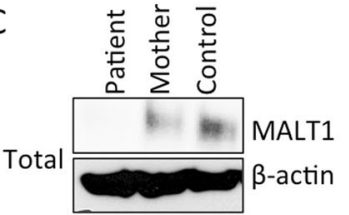

(CD45RA+, FoxP3+) and active (CD45RA-, FoxP3+) Treg cells in PBMCs from patient autologous and donor populations, the mother; and a healthy control. c, MALT1 protein expression in total cell lysates isolated from PBMCs from the patient autologous cells, maternal cells and cells from a healthy control. Beta-actin was used as a loading control. All data representative of 3 independent experiments
IFN- $\gamma$, but the patient's autologous, MALT1-defective T cells had little of either cytokine (Fig. 3b). Similar results were observed in PBMCs stimulated by the superantigen SEE or antiCD3 plus anti-CD28 (Suppl Figure 2).

Reconstitution of Impaired NF-kB Signaling in MALT1 Defective Epstein-Barr Virus Transformed B Cell Lines

A pure TRA2G9-positive MALT1 defective sub-line was expanded from sorted patient EBV cells. This and a control EBV line were analyzed at rest and following stimulation, showing the same inability as T cells to phosphorylate NF- $\mathrm{KB}$ or degrade $\mathrm{I} \kappa \mathrm{B}$ in response to PMA and ionomycin (Fig. $3 \mathrm{c}$ and not shown). To conclusively implicate MALT1 in the functional deficits observed in CBM complex formation and downstream signaling, patient EBV cells were transduced with MP283 lentiviruses expressing mCherry alone or WT MALT1 cDNA and mCherry. While the former had no effect (Fig. 3c, middle panels), the vector restoring MALT1 normalized both NF-KB phosphorylation and IKB destruction (Fig. 3c, bottom panels). 
A
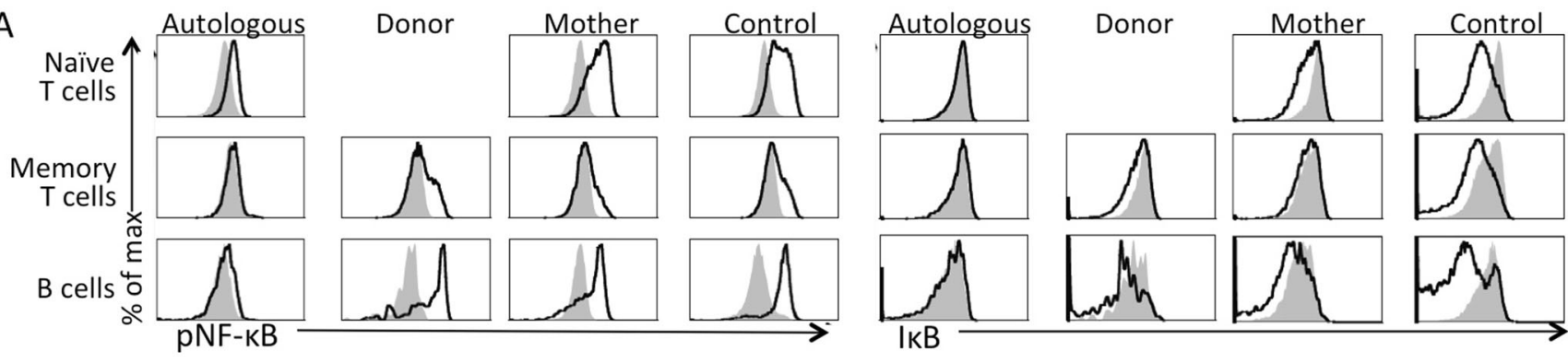

B
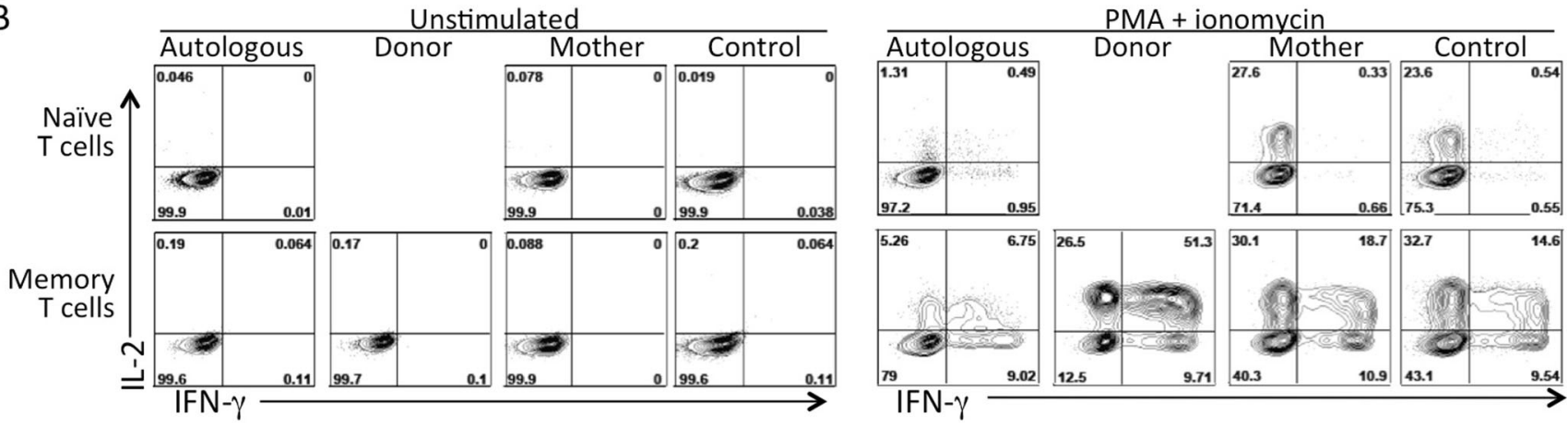

C
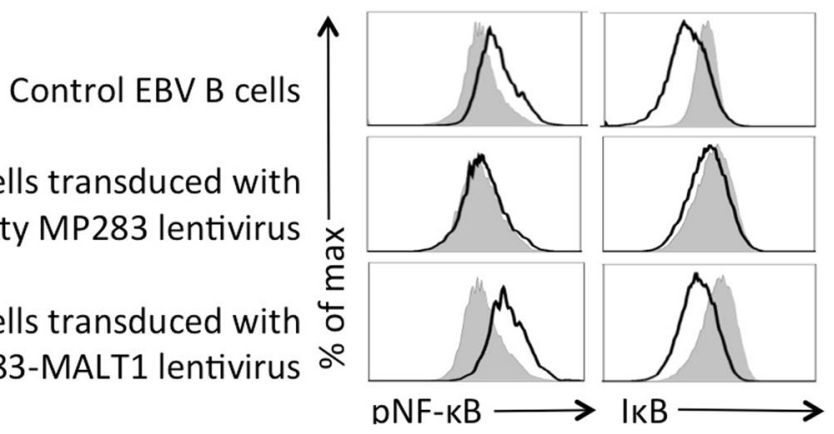

Fig. 3 a, Intracellular phospho-NF-kB and I $\mathrm{B}$ in gated unstimulated (gray shading) vs. PMA and ionomycin stimulated (black line) naïve and memory CD3 + T cells and CD19+ B cells from the patient, including patient autologous (TRA2G9+) and donor-derived (TRA2G9-) cells; also analyzed were cells from the mother and a healthy control. b, T cell expression of intracellular IL-2 (y-axis) and IFN- $\gamma$ (x-axis) without (left panels) and with (right panels) PMA plus ionomycin stimulation. c,

Analysis of NF- $\mathrm{kB}$ phosphorylation and IкB degradation without (gray shading) or with (black lines) stimulation with PMA and ionomycin. Upper panels, control EBV B cells; middle panels, patient autologous EBV B cells transduced with empty MP283 lentivirus; bottom panels, patient autologous EBV B cells transduced with MP283-MALT1 lentivirus. All data representative of 3 independent experiments

\section{Discussion}

Our patient with profound CID and dysregulation adds to the 2 prior reports and extends our understanding of MALT1associated disease and its therapy [22, 23]. Like the prior cases (Table 2), our patient had functionally impaired T and B cells leading to recurrent bacterial and viral infections from early life, notably with CMV, which in our patient was not controlled by antiviral therapy and required postHCT donor $\mathrm{T}$ cell infusions for resolution. While HCT was recently postulated as treatment for MALT1-deficient CID [24], our report is the first of a MALT1-deficient patient cured by HCT. Two prior siblings died in childhood and a surviving teenager suffers significant multi-organ disease, including $\mathrm{T}$ cell inflammation of the skin and bowel similar to that in our patient.
MALT1 mutant patients reported to date had variable B cell numbers, serum immunoglobulin levels and ability to make specific antibodies (Table 2). Immune dysregulation consisting of prominent rash and suspected inflammatory bowel disease was shared between our patient and the living girl with W580S mutation [23]. In contrast to that patient, however, ours had normal B cell numbers, no IgE elevation and (like the deceased children with S89I mutation) absent protective antibody production.

Our patient's MALT1 compound heterozygous mutations resulted in undetectable protein and MALT1 function. As with the previous reports, after introduction of wild type MALT1 cDNA, our patient's mutant cells had MALT1 expression and NF- $\mathrm{BB}$ signaling reconstituted. Our case also highlights how MALT1 mutations may lead to immune dysregulation and autoimmunity. After HCT, almost all Tregs and all active 
Tregs in our patient's PBMCs were donor-derived (Fig. 2b), accounting for the pre-HCT failure of autologous T cells to control auto-reactive attack on the skin and possibly the intestinal tract. The mixed chimerism exhibited by our patient postHCT allowed us to evaluate both wild type and MALT1 deficient lymphocytes that had developed from hematopoietic progenitors in vivo. Moreover, our patient's disease resolved even though he received a non-myeloablative preparative regimen (due to his high risk status with ongoing CMV infection) that did not result in a substantial circulating naïve $T$ cell population. Whether the donor $\mathrm{T}$ cells originated from limited thymic development from CD34 progenitors vs. expanded donor T cells, or a combination of both, cannot be determined. However, the patient's successful outcome indicates that only $15 \%$ of donor T cells were sufficient to reconstitute functional immunity and immune regulation.

The two heterozygous mutations in our patient abrogated MALT1 protein expression. Whereas the p.Y353fs*18 transcript was, as expected, degraded by nonsense-mediated mRNA decay, full-length transcripts skipping exon 10, due to the splice acceptor site defect, were also not detectable. MALT1 protein normally shuttles between the cytoplasm and nucleus with the aid of a nuclear export signal (NES1) $[31,32]$ and a regulatory region for NES1 encoded in exon 10 , as well as second NES (NES2) in the C-terminal region of the protein $[33,34]$. If a transcript missing exon 10 had been stable in our patient, the resulting protein might have been trapped in the nucleus. However, no nuclear or cytoplasmic protein from autologous patient cells was detected.

The high degree of consanguinity in the previously reported patients may indicate that loci other than MALT1 modified their immune phenotype as well as contributing to delayed bone age, fractures, short stature, and dysmorphia in the surviving patient and poor growth in the deceased siblings; these features were absent in our outbred patient who had compound heterozygosity at the MALT1 locus and has regained normal weight and stature following HCT.

Malt1-/- mice have defects in TCR activation and cytokine production similar to those observed in humans with MALT1 deficiency [10, 35]. Malt1- - mice demonstrate diverse $B$ cell defects, as have humans, with NF- $\mathrm{kB}$ activity in B cells reduced in one report [36], but only marginally altered after immunoglobulin receptor engagement in another [35]. Mice deficient in CBM complex proteins have reduced thymic Treg cells [37, 38], but this has not been described in mice lacking Malt1. While the recently discovered human patients with CARD11 mutations had Treg deficiency, similar to the mouse model [20, 21], and Tregs were either normal or not studied in the previously described patients with MALT1 mutations, our patient's autologous PBMCs had nearly absent Tregs and very low levels of Foxp3 expression. Thus, although Malt1 appears not to be required for development of Tregs in mice, it may be important in humans, in keeping with our patient's resolution of dysregulated immune phenotypes following HCT that provided donor-derived Tregs.

When determining the underlying cause of immune deficiencies without lymphopenia and with normal TREC numbers, signaling molecules downstream of the antigen receptors have become candidates for analysis. As shown by our patient and others with defects in MALT1, as well as patients lacking CARMA1, NF- $\mathrm{KB}$ essential modulator, and IKK2 (IKBKB) [39], proteins important in antigen receptor and NF-KB signaling should be investigated in patients with combined immunodeficiency.

\section{Conclusions}

MALT1 deficiency can cause infantile combined immunodeficiency and immune dysregulation without $\mathrm{T}$ cell lymphopenia, but with impaired lymphocyte signaling through NF-kB, failure to generate memory and regulatory $\mathrm{T}$ cells, and hypogammaglobulinemia. Hematopoietic cell transplantation can be curative.

Acknowledgments We thank the patient and his family for their participation, the clinicians who provided skillful care, and Yanning Wang, Karly Kondratowicz and Misako Stillion for expert technical assistance. We thank Dr. Jar-How Lee (Thermo Fisher Scientific) for kindly providing a monoclonal antibody against HLA-C*3. This work was supported by NIH R01 AI078248, R01 AI105776 (JMP, SEB); U54 AI 082973 (MJC, JMP); the UCSF Jeffrey Modell Foundation Diagnostic Center for Primary Immunodeficiencies; Tata Consultancy Services (SEB, US, RS) and the Howard Hughes Medical Institute (AW). H.W. was supported by the Arthritis Foundation.

Open Access This article is distributed under the terms of the Creative Commons Attribution License which permits any use, distribution, and reproduction in any medium, provided the original author(s) and the source are credited.

\section{References}

1. Al-Herz W, Bousfiha A, Casanova JL, Chatila T, Conley ME, Cunningham-Rundles $\mathrm{C}$, et al. Primary immunodeficiency diseases: an update on the classification from the international union of immunological societies expert committee for primary immunodeficiency. Front Immunol. 2014;5:162. doi:10.3389/fimmu.2014.00162.

2. Buckley RH. The multiple causes of human SCID. J Clin Invest. 2004;114(10):1409-11. doi:10.1172/JCI23571.

3. Gaspar HB, Aiuti A, Porta F, Candotti F, Hershfield MS, Notarangelo LD. How i treat ADA deficiency. Blood. 2009;114(17):3524-32. doi: 10.1182/blood-2009-06-189209.

4. Ochs HD, Puck J. Primary Immunodeficiency Diseases, A Molecular and Genetic Approach. 2nd ed. 2006-7.

5. Feske S. ORAI1 and STIM1 deficiency in human and mice: roles of store-operated $\mathrm{Ca} 2+$ entry in the immune system and beyond. 
Immunol Rev. 2009;231(1):189-209. doi:10.1111/j.1600-065X. 2009.00818.x.

6. Griscelli C, Lisowska-Grospierre B, Mach B. Combined immunodeficiency with defective expression in MHC class II genes. Immunodefic Rev. 1989;1(2):135-53.

7. Puck JM. Neonatal screening for severe combined immunodeficiency. Curr Opin Pediatr. 2011;23(6):667-73. doi:10.1097/MOP. 0b013e32834cb9b0.

8. Ghosh S, May MJ, Kopp EB. NF-kappa B and Rel proteins: evolutionarily conserved mediators of immune responses. Annu Rev Immunol. 1998;16:225-60. doi:10.1146/annurev.immunol.16.1.225.

9. Thome M, Charton JE, Pelzer C, Hailfinger S. Antigen receptor signaling to NF-kappaB via CARMA1, BCL10, and MALT1. Cold Spring Harb Perspect Biol. 2010;2(9):a003004. doi:10.1101/ cshperspect.a003004.

10. Ruefli-Brasse AA, French DM, Dixit VM. Regulation of NFkappaB-dependent lymphocyte activation and development by paracaspase. Science. 2003;302(5650):1581-4. doi:10.1126/ science.1090769.

11. Thome M, Tschopp J. TCR-induced NF-kappaB activation: a crucial role for Carma1, Bcl10 and MALT1. Trends Immunol. 2003;24(8): 419-24.

12. Qiao Q, Yang C, Zheng C, Fontan L, David L, Yu X, et al. Structural architecture of the CARMA1/Bcl10/MALT1 signalosome: nucleation-induced filamentous assembly. Mol Cell. 2013;51(6): 766-79. doi:10.1016/j.molcel.2013.08.032.

13. Ruland J, Mak TW. Transducing signals from antigen receptors to nuclear factor kappaB. Immunol Rev. 2003;193:93-100.

14. Thome M. CARMA1, BCL-10 and MALT1 in lymphocyte development and activation. Nat Rev Immunol. 2004;4(5):348-59. doi:10. 1038/nri1352.

15. Oeckinghaus A, Wegener E, Welteke V, Ferch U, Arslan SC, Ruland $\mathrm{J}$, et al. Malt1 ubiquitination triggers NF-kappaB signaling upon Tcell activation. EMBO J. 2007;26(22):4634-45. doi:10.1038/sj. emboj.7601897.

16. Sun L, Deng L, Ea CK, Xia ZP, Chen ZJ. The TRAF6 ubiquitin ligase and TAK1 kinase mediate IKK activation by BCL10 and MALT1 in T lymphocytes. Mol Cell. 2004;14(3):289-301.

17. Zhou H, Wertz I, O'Rourke K, Ultsch M, Seshagiri S, Eby M, et al. Bcl10 activates the NF-kappaB pathway through ubiquitination of NEMO. Nature. 2004;427(6970):167-71. doi:10.1038/nature02273.

18. Orange JS, Geha RS. Finding NEMO: genetic disorders of NF[kappa]B activation. J Clin Invest. 2003;112(7):983-5. doi:10.1172/ JCI19960.

19. Zonana J, Elder ME, Schneider LC, Orlow SJ, Moss C, Golabi M, et al. A novel $\mathrm{X}$-linked disorder of immune deficiency and hypohidrotic ectodermal dysplasia is allelic to incontinentia pigmenti and due to mutations in IKK-gamma (NEMO). Am J Hum Genet. 2000;67(6):1555-62. doi:10.1086/316914.

20. Greil J, Rausch T, Giese T, Bandapalli OR, Daniel V, BekeredjianDing I, et al. Whole-exome sequencing links caspase recruitment domain 11 (CARD11) inactivation to severe combined immunodeficiency. J Allergy Clin Immunol. 2013;131(5):1376-83 e3. doi:10. 1016/j.jaci.2013.02.012

21. Stepensky P, Keller B, Buchta M, Kienzler AK, Elpeleg O, Somech $\mathrm{R}$, et al. Deficiency of caspase recruitment domain family, member 11 (CARD11), causes profound combined immunodeficiency in human subjects. J Allergy Clin Immunol. 2013;131(2):477-85 e1. doi:10. 1016/j.jaci.2012.11.050.

22. Jabara HH, Ohsumi T, Chou J, Massaad MJ, Benson H, Megarbane A, et al. A homozygous mucosa-associated lymphoid tissue 1 (MALT1) mutation in a family with combined immunodeficiency. $\mathrm{J}$ Allergy Clin Immunol. 2013;132(1):151-8. doi:10.1016/j.jaci.2013. 04.047.

23. McKinnon ML, Rozmus J, Fung SY, Hirschfeld AF, Del Bel KL, Thomas L, et al. Combined immunodeficiency associated with homozygous MALT1 mutations. J Allergy Clin Immunol. 2013. doi:10.1016/j.jaci.2013.10.045.

24. Turvey SE, Durandy A, Fischer A, Fung SY, Geha RS, Gewies A, et al. The CARD11-BCL10-MALT1 (CBM) signalosome complex: Stepping into the limelight of human primary immunodeficiency. J Allergy Clin Immunol. 2014;134(2):276-84. doi:10.1016/j.jaci. 2014.06.015.

25. Mallott J, Kwan A, Church J, Gonzalez-Espinosa D, Lorey F, Tang LF, et al. Newborn screening for SCID identifies patients with ataxia telangiectasia. J Clin Immunol. 2013;33(3):540-9. doi:10.1007/ s10875-012-9846-1.

26. Chan K, Puck JM. Development of population-based newborn screening for severe combined immunodeficiency. J Allergy Clin Immunol. 2005;115(2):391-8. doi:10.1016/j.jaci.2004.10.012.

27. Mulder A, Kardol MJ, Uit het Broek CM, Tanke-Visser J, Young NT, Claas FH. A human monoclonal antibody against HLA-Cw1 and a human monoclonal antibody against an HLA-A locus determinant derived from a single uniparous female. Tissue Antigens. 1998;52(4):393-6.

28. Zoet YM, Eijsink C, Bohmova R, Witvliet MD, Kardol MJ, Franke ME, et al. Single-antigen-expressing cell lines are excellent tools for detecting human leukocyte antigen-C-reactive antibodies in kidney transplant recipients. Transplantation. 2005;79(9):1268-72.

29. Duquesnoy RJ, Marrari M, Jelenik L, Zeevi A, Claas FH, Mulder A. Structural aspects of HLA class I epitopes reacting with human monoclonal antibodies in Ig-binding, C1q-binding and lymphocytotoxicity assays. Hum Immunol. 2013;74(10):1271-9. doi:10.1016/j. humimm.2013.05.016.

30. Yu JW, Jeffrey PD, Ha JY, Yang X, Shi Y. Crystal structure of the mucosa-associated lymphoid tissue lymphoma translocation 1 (MALT1) paracaspase region. Proc Natl Acad Sci U S A. 2011;108(52):21004-9. doi:10.1073/pnas.1111708108.

31. Nakielny S, Dreyfuss G. Nuclear export of proteins and RNAs. Curr Opin Cell Biol. 1997;9(3):420-9.

32. Kau TR, Way JC, Silver PA. Nuclear transport and cancer: from mechanism to intervention. Nat Rev Cancer. 2004;4(2):106-17. doi: $10.1038 / \mathrm{nrc1} 274$.

33. Izumiyama K, Nakagawa M, Yonezumi M, Kasugai Y, Suzuki R, Suzuki H, et al. Stability and subcellular localization of API2MALT1 chimeric protein involved in $\mathrm{t}(11 ; 18)(\mathrm{q} 21 ; \mathrm{q} 21)$ MALT lymphoma. Oncogene. 2003;22(50):8085-92. doi:10.1038/sj.onc. 1207002.

34. Nakagawa M, Hosokawa Y, Yonezumi M, Izumiyama K, Suzuki R, Tsuzuki S, et al. MALT1 contains nuclear export signals and regulates cytoplasmic localization of BCL10. Blood. 2005;106(13): 4210-6. doi:10.1182/blood-2004-12-4785.

35. Ruland J, Duncan GS, Wakeham A, Mak TW. Differential requirement for Malt1 in T and B cell antigen receptor signaling. Immunity. 2003;19(5):749-58.

36. Ferch U, zum Buschenfelde CM, Gewies A, Wegener E, Rauser S, Peschel C, et al. MALT1 directs B cell receptor-induced canonical nuclear factor-kappaB signaling selectively to the c-Rel subunit. Nat Immunol. 2007;8(9):984-91. doi:10.1038/ni1493.

37. Schmidt-Supprian M, Tian J, Grant EP, Pasparakis M, Maehr R, Ovaa $\mathrm{H}$, et al. Differential dependence of $\mathrm{CD} 4+\mathrm{CD} 25+$ regulatory and natural killer-like $\mathrm{T}$ cells on signals leading to NF-kappaB activation. Proc Natl Acad Sci U S A. 2004;101(13):4566-71. doi:10. 1073/pnas.0400885101.

38. Molinero LL, Yang J, Gajewski T, Abraham C, Farrar MA, Alegre ML. CARMA1 controls an early checkpoint in the thymic development of FoxP3+ regulatory T cells. J Immunol. 2009;182(11):673643. doi:10.4049/jimmunol.0900498.

39. Pannicke U, Baumann B, Fuchs S, Henneke P, Rensing-Ehl A, Rizzi $\mathrm{M}$, et al. Deficiency of innate and acquired immunity caused by an 
IKBKB mutation. N Engl J Med. 2013;369(26):2504-14. doi:10. 1056/NEJMoa1309199.

40. Li H, Durbin R. Fast and accurate short read alignment with Burrows-Wheeler transform. Bioinformatics. 2009;25(14):1754-60. doi:10.1093/bioinformatics/btp324.

41. DePristo MA, Banks E, Poplin R, Garimella KV, Maguire JR, Hartl $\mathrm{C}$, et al. A framework for variation discovery and genotyping using next-generation DNA sequencing data. Nat Genet. 2011;43(5):4918. doi:10.1038/ng.806.
42. McKenna A, Hanna M, Banks E, Sivachenko A, Cibulskis K, Kernytsky A, et al. The Genome Analysis Toolkit: a MapReduce framework for analyzing next-generation DNA sequencing data. Genome Res. 2010;20(9):1297-303. doi:10.1101/gr.107524.110.

43. Cingolani P, Platts A, le Wang L, Coon M, Nguyen T, Wang L, et al. A program for annotating and predicting the effects of single nucleotide polymorphisms, SnpEff: SNPs in the genome of Drosophila melanogaster strain w1118; iso-2; iso-3. Fly. 2012;6(2):80-92. doi: 10.4161/fly. 19695 . 